\title{
An Adaptive Control Strategy for a Low-Ripple Boost Converter in BLDC Motor Speed Control
}

Research paper

\author{
Haifeng Wang ${ }^{1, *}$, Haili Zhang ${ }^{2}$ \\ ${ }^{1}$ Penn State University, 3550 7th Street Rd, New Kensington, PA 15068, USA \\ ${ }^{2}$ Penn State University, 30 East Swedesford Rd, Malvern, PA 19355, USA
}

Received: September 04, 2021; Accepted: October 12, 2021

\begin{abstract}
Conventional boost converters are widely used for connecting low-voltage power sources and inverters in motor control. However, a large filter capacitor bank is often used to reduce DC-link ripples that occur when an inverter is connected to a boost converter. Otherwise, significant voltage and current perturbations can impact on battery performance degradation and cause torque ripple, speed ripple and vibration in brushless DC (BLDC) motors. To suppress the converter's DC-link ripple, this paper proposes a new control strategy for boost converter controller to generate low-ripple DC-link voltage or current at different motor speeds. In the proposed method, observers are designed to adaptively estimate the DC-link voltage and current harmonics. The harmonic terms are used as feedback signals to calculate the DC converter's duty cycle. The entire control model is implemented on an embedded system, and its robustness is verified by simulation and experimental results that show the DC-link voltage and current ripples can be reduced by about $50 \%$ and $30 \%$, respectively.
\end{abstract}

Keywords: boost converter $\bullet B L D C \cdot$ harmonics $\bullet$ observer $\bullet$ feedback control

\section{Introduction}

Boost converters play an important role in processing high power requirement with high efficiency and dynamics (Aljarajreh et al., 2019; Jung et al., 2014; Nahavandi et al., 2015). DC boost converters can be used for most suitable DC power supplies, such as batteries, solar panels, rectifiers, or DC generators. The DC-DC converter can convert a certain DC voltage into a different DC voltages. Battery-powered systems generally connect batteries in series to increase output voltage (Bamgboje et al., 2019; Nguyen et al., 2018). However, in many high-voltage applications, due to space constraints, it is impossible to connect lots of batteries in series to generate the required high voltage. In the last few years, high step-up DC-DC converters have been widely used due to its wide applicability (Ullah, 2021; Wang and Hu, 2020), especially considering that DC-AC converters must be typically supplied with high DC voltages (Racewicz et al., 2018). Considerable efforts have been directed to the control of efficient boost converters to maximise the efficiency (Forouzesh et al., 2017; Tofoli et al., 2015; Waradzyn et al., 2018). The boost converter can step-up the DC voltage and reduce the number of batteries required. For example, electric vehicles (EVs) and lighting systems are systems that use batteries to supply power with boost converters. Figure 1 shows the components in $\mathrm{EV}$ power conversion architecture, which first converts $\mathrm{DC}$ to $\mathrm{AC}$, and then electric motors convert electrical energy into physical movement. In most motor drive systems, the major load of a boost converter is typically an inverter followed by a motor (Axelrod et al., 2009; Wu et al., 2016).

The DC-link voltage in converter-inverter circuits always has ripples because the $\mathrm{H}$-bridge inverter draws a current with harmonics twice the frequency of the inverter output current. The ripple increases as the output power is increased (Liu et al., 2020; Rashed et al., 2010). For example, if EVs are connected with an electrical grid, the charging and discharging converter-inverter circuits will induce extra ripples in the order of twice the grid frequency 


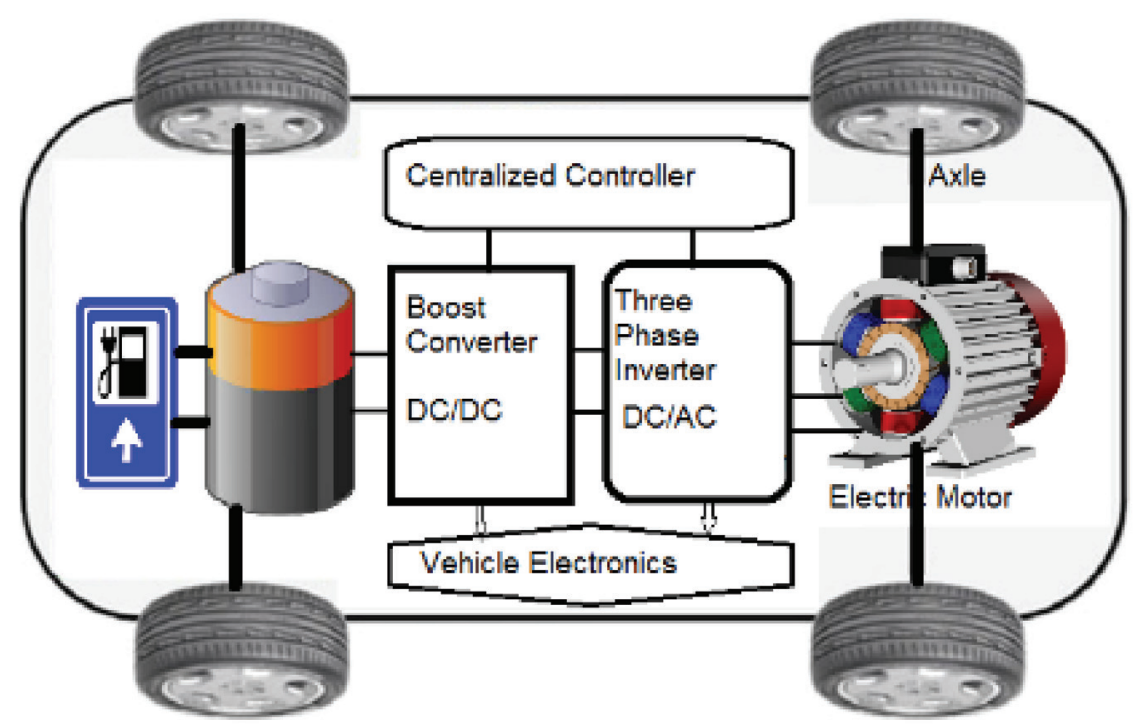

Fig. 1. EV power conversion architecture diagram. EV, electric vehicle.

(Uddin et al., 2016; Zhong and Konstantopoulos, 2016). The presence of ripple is an important consideration in DC-DC converter applications (Wang, 2019). The ripple level can be sufficiently high to adversely affect other devices and parts connected with converters if ripples are unfiltered. Ripples can cause distortion and power loss as well as generate unnecessary torque ripples (Wang, 2019). High frequency current ripples that enter batteries can age batteries and cause deterioration of the anions' state of equilibrium (Devarakonda et al., 2014; Shi et al., 2018; Uddin et al., 2016; Wang et al., 2016).

Within the EV powertrain, a low-pass filter is commonly used to eliminate these harmonics. However, it is almost impossible to eliminate them, but can only decrease them (Amamra et al., 2020). There are various shortcomings in the method of using filters. To reduce ripples, interleaved boost converters (IBC) containing a large-capacity filter have been investigated. But they require shifting of several channels and have more Integrated circuit (IC) components that increase cost and space (Gu and Zhang, 2012). In addition, they generate higher frequency ripples and power losses due to the channels' switch (Wen and Su, 2016; Wen et al., 2014; Yang et al., 2015). In noise sensitive applications, an external proportional-integral filter can be connected to a converter. The first step is to choose an inductor of large inductance. Large inductance will require a large capacitance, and the response of the filter could be significantly slowed. Adding an ultra-low-noise low-dropout regulator (LDO), to the converter output is another way to achieve low noise outputs (Wang, 2019). However, a LDO can handle only a limited current and also needs large capacitors working with it (Tay et al., 2012).

The motor supply voltage contains various harmonic components that always cause torque ripples. Torqueripple control of brushless DC (BLDC) motor has been a main challenge in motor drive systems (Deng et al., 2017). So, multifarious efficient controllers have been designed to reduce the harmonics present in the input voltage. In Doss et al. (2013), model predictive control (MPC) was used to generate the pulses to the gate circuit of three phase inverter. Chen et al. (2017) presented a new method which depends on Genetic Algorithms to search for the Fourier coefficients of three-phase stator currents for a given back electromotive force (back EMF) waveforms. Prathibanandhi and Ramesh (2018) proposed a strategy which combined the adaptive neuro-fuzzy inference system with firefly algorithm. Based on a novel fuzzy adaptive speed controller and an adaptive weighting factor, Zhang et al. (2021) proposed an improved Finite control set-model predictive torque control (FCS-MPTC) strategy to reduce the speed, torque and flux ripples. The research reduced torque ripples by the proposed strategies but did not reduce DC-DC converter's output voltage ripple.

This paper proposed a method to reduce the DC-link ripples for a typical two-stage converter-inverter motor drive circuit that consists of a boost converter cascaded by a three-phase full-bridge inverter and a BLDC motor, as depicted in Figure 2 (Wang, 2019). The proposed method involves a seventh-order observer in a linear timeinvariant system (LTI) converter control system. This observer-based control method is applied to reduce battery ripple current, inductor current ripple and DC-link voltage ripple. Moreover, the observer can adaptively update the 


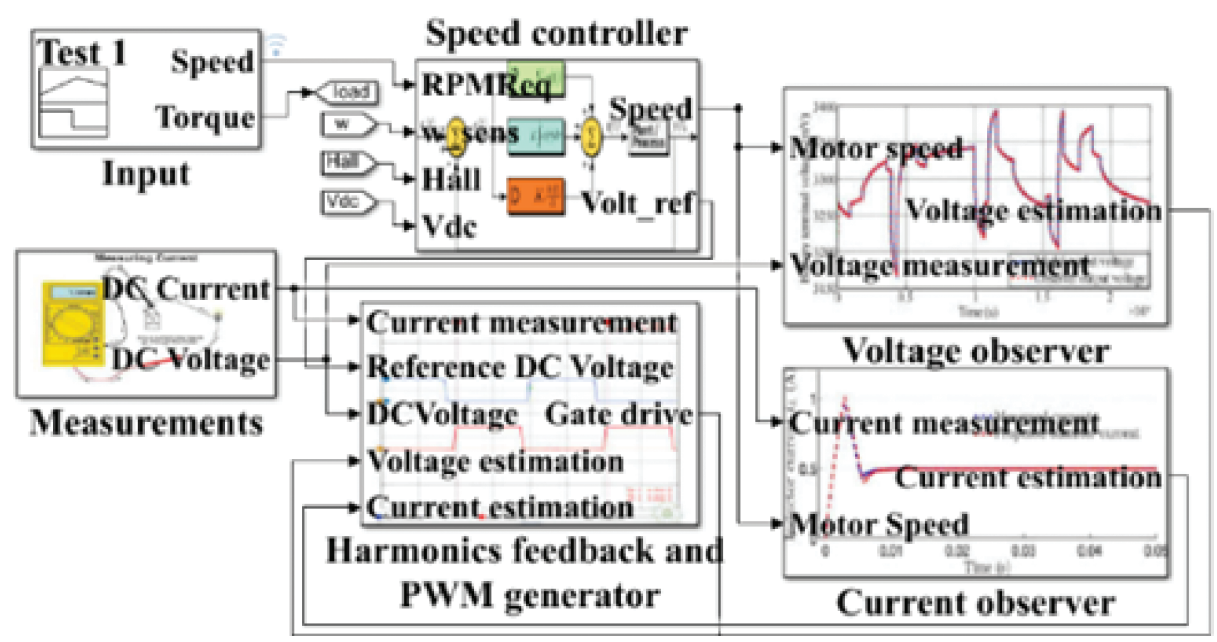

(a)

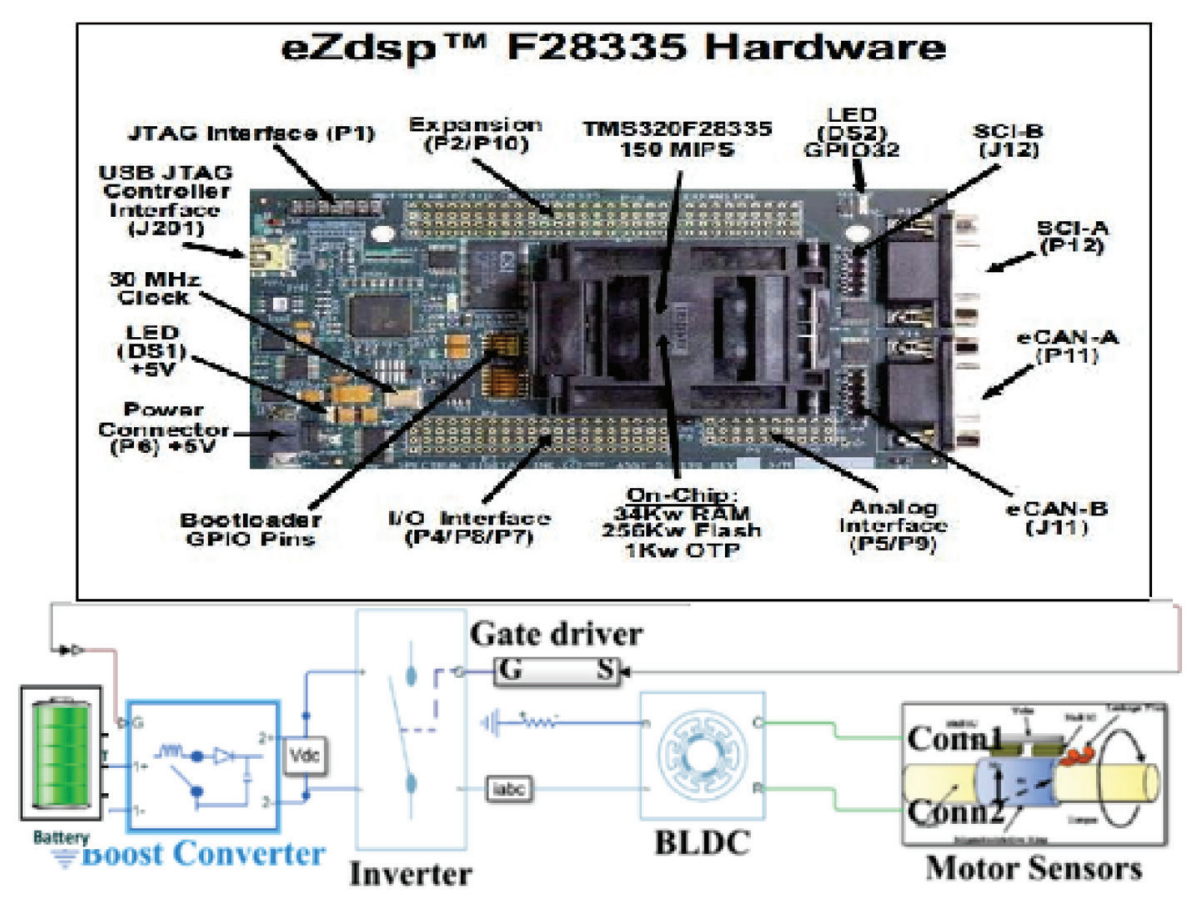

(b)

Fig. 2. The proposed controller (a) was programmed and downloaded into the digital signal processor (DSP) board (b) to control a BLDC motor. BLDC, brushless DC.

voltage and current harmonics frequency to the controller based on the real-time motor speed. The motor speed is measured and used in the calculation of the harmonics to estimate the DC-link ripple's amplitude, phase and frequency.

A cascaded proportional plus integral (PI) controller reported in Darba et al. (2015) controls the speed of a selfsensing BLDC. The speed tracking response is accurate and speed ripple is reduced due to reduced DC voltage ripple. The parameters of the PI controller can be tuned in several ways. This paper will also introduce a cascaded control strategy. A PI controller calculates the DC-link reference voltage, and the voltage is used as a reference input to an inner boost converter control loop. 


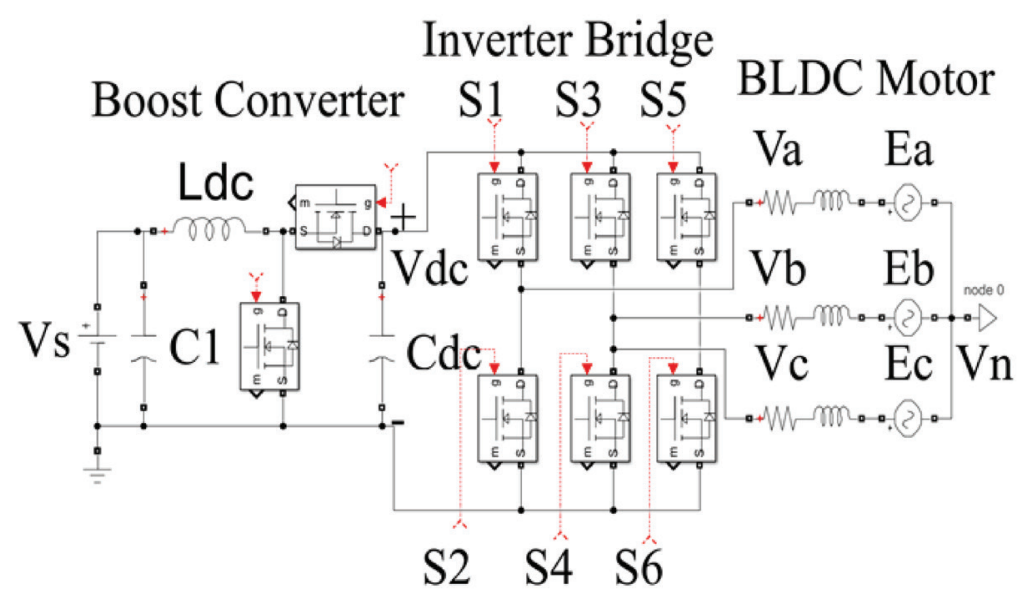

Fig. 3. The circuit topology for the two-stage booster inverter.

\section{Feedback Control Design for Robust Reference Tracking and Ripple Reduction}

\subsection{Extracting ripple harmonics via an observer}

Suppose a boost converter-inverter circuit is a LTI system represented by its states. If the system is observable, its states such as voltage and current can be reconstructed or evaluated by an observer (Wang, 2019). The following section explains how the DC-link harmonics are related to the state of the LTI system and how to construct state observers with standard procedure (Fassinou et al., 2014).

In Figure 3, the DC-link voltage $v_{d c}$ at steady state can be expressed as

$$
v_{d c}(t)=v_{a}+\sum_{n=1}^{\infty} b_{n} \cos \left(n \beta t+\varnothing_{n}\right)
$$

where $v_{a}$ is the average value of $v_{d c}$, and $b_{n}$ as well as $\varnothing_{n}$ are the magnitude and phase for the nth-order harmonics. (measured in radians) is the frequency of the DC-link ripple and is adaptively adjusted based on motor speed ratio. The first three harmonics will be sufficient to significantly reduce the ripple; therefore, this paper considers only the first three harmonics. Then

$$
v_{d c}(t)=v_{a}+b_{1} \cos \left(\beta t+\varnothing_{1}\right)+b_{2} \cos \left(2 \beta t+\varnothing_{2}\right)+b_{3} \cos \left(3 \beta t+\varnothing_{3}\right)
$$

DC-link voltage $v_{d c}$ and inductor current are the output of a seventh-order autonomous LTI system. Define

$$
S=\left[\begin{array}{ccccccc}
0 & 0 & 0 & 0 & 0 & 0 & 0 \\
0 & 0 & -\beta & 0 & 0 & 0 & 0 \\
0 & \beta & 0 & 0 & 0 & 0 & 0 \\
0 & 0 & 0 & 0 & -2 \beta & 0 & 0 \\
0 & 0 & 0 & 2 \beta & 0 & 0 & 0 \\
0 & 0 & 0 & 0 & 0 & 0 & -3 \beta \\
0 & 0 & 0 & 0 & 0 & 3 \beta & 0
\end{array}\right]
$$

$G=\left[\begin{array}{lllllll}1 & 1 & 0 & 1 & 0 & 1 & 0\end{array}\right]$

And denote the state of the LTI system as $x \in R^{7}$, then, to analyse the voltage $v_{d c}$ first:

$v_{d c}=G x, \dot{x}=S x, x(0)=x_{0}$ 
Table 1. Fundamental and harmonics for the DC-link voltage

\begin{tabular}{ll}
\hline Quantity & Symbol \\
\hline \hline Fundamental component & $v_{a}$ \\
First-order harmonic & $b_{1} \cos \varnothing_{1}$ \\
First-order harmonic derivative & $b_{1} \sin \varnothing_{1}$ \\
Second-order harmonic & $b_{2} \cos \varnothing_{2}$ \\
Second-order harmonic derivative & $b_{2} \sin \varnothing_{2}$ \\
Third-order harmonic & $b_{3} \cos \varnothing_{3}$ \\
Third-order harmonic derivative & $b_{3} \sin \varnothing_{3}$ \\
\hline
\end{tabular}

The Eqs (1) and (2) can be related via the following equations:

$$
\begin{aligned}
& v_{a}=x_{1}(t), x_{01}=v_{a} \\
& b_{1} \cos \left(\beta t+\varnothing_{1}\right)=x_{2}(t),\left[\begin{array}{l}
x_{02} \\
x_{03}
\end{array}\right]=\left[\begin{array}{l}
b_{1} \cos \varnothing_{1} \\
b_{1} \sin \varnothing_{1}
\end{array}\right] \\
& b_{2} \cos \left(2 \beta t+\varnothing_{2}\right)=x_{4}(t),\left[\begin{array}{l}
x_{04} \\
x_{05}
\end{array}\right]=\left[\begin{array}{l}
b_{2} \cos \varnothing_{2} \\
b_{2} \sin \varnothing_{2}
\end{array}\right] \\
& b_{3} \cos \left(3 \beta t+\varnothing_{3}\right)=x_{6}(t),\left[\begin{array}{l}
x_{06} \\
x_{07}
\end{array}\right]=\left[\begin{array}{l}
b_{3} \cos \varnothing_{3} \\
b_{3} \sin \varnothing_{3}
\end{array}\right]
\end{aligned}
$$

This means that each harmonic can be reconstructed by two of the state variables. Since the pair (S, G) is observable, all its states can be reconstructed from its output $v_{d c}$, which can be easily measured by use of A/D converters. It follows that, from the average of $v_{d c}$, all its harmonics and their derivatives can be extracted from $v_{d c}$ via an observer, as shown in Table 1.

Based on the technology that deals with unwanted periodical signals (Hu et al., 2005; Jung et al., 2014), feedback control is constructed by using both the harmonics, which are represented by $x_{2}, x_{4}$ and $x_{6}$, and their derivatives: $x_{3}, x_{5}$ and $x_{7}$.

\subsection{Estimation of the harmonics via observers}

Let the state of the observer be $z$ and the input be $v_{d c}$ :

$$
\dot{z}=(S-L G) z+L v_{d c}
$$

Let the observer error be $e=z-x$ and $\dot{e}=(S-L G) e$. This implies that the observer error will go to 0 as $t$ tends to infinity if $S-L G$ is stable. $L$ is the observer gain. Because of measurement errors, noise and high frequency switching ripples, the gain $L$ should be kept within a reasonable range for acceptable convergence rate and to avoid over amplifying noises.

When the estimation error $e$ is sufficiently small, the observer state $z$ is very close to state $x$ of the LTI system. The harmonics of $v_{d c}$ and their derivatives can be extracted from the state $z$. Then state $z$ can be used in feedback control to calculate duty cycles of the boost converter.

\subsubsection{Using the estimated harmonics for feedback}

Suppose that the current $i_{L}$ of the inductor $L_{d c}$ is represented by a voltage across a resistor. Let the desired DC-link voltage be $v_{r e f}$. A simple feedback control to achieve robust tracking is represented by

$$
D=D_{0}+k_{1}\left(i_{L}-i_{L 0}\right)+k_{2}\left(v_{d c}-v_{r e f}\right)+k_{3} \int\left(v_{d c}-v_{r e f}\right) d t
$$

where $D$ represents the duty cycle of the PWM signal for the low side metal-oxide-semiconductor field-effect transistor (MOSFET) switch of the half-bridge in the boost converter in Figure $3 . D_{0}$ is a nominal duty cycle. $i_{L 0}$ 
is the nominal inductor current. To reduce DC-link voltage ripple, an extra term, $K^{*} z$, is added to the feedback control:

$$
D=D_{0}+k_{1}\left(i_{L}-i_{L 0}\right)+k_{2}\left(v_{d c}-v_{r e f}\right)+k_{3} \int\left(v_{d c}-v_{r e f}\right) d t+K *_{z}
$$

\subsubsection{The discretised observer and digital implementation}

The LTI system needs to be discretised for implementation in a microcontroller. Let the sampling time be $T$ and the discretised state be $x[k]=x(k T)$. The discretised LTI system is

$$
v_{d c}[k]=G x[k], x[k+1]=S_{d} x[k], x[0]=x_{0}
$$

where

$$
S_{d}=e^{S * \frac{\omega}{1000} * t}=\left[\begin{array}{ccccccc}
1 & 0 & 0 & 0 & 0 & 0 & 0 \\
0 & \cos \beta T & \sin \beta T & 0 & 0 & 0 & 0 \\
0 & -\sin \beta T & \cos \beta T & 0 & 0 & 0 & 0 \\
0 & 0 & 0 & \cos 2 \beta T & \sin 2 \beta T & 0 & 0 \\
0 & 0 & 0 & -\sin 2 \beta T & \cos 2 \beta T & 0 & 0 \\
0 & 0 & 0 & 0 & 0 & \cos 3 \beta T & \sin 3 \beta T \\
0 & 0 & 0 & 0 & 0 & -\sin 3 \beta T & \cos 3 \beta T
\end{array}\right]
$$

Similarly, the state observer is represented by

$$
z[k+1]=S_{d} z[k]+L_{d}\left(v_{d c}[k]-G z[k]\right)
$$

where $L_{d}$ is chosen so that the eigenvalues of $S_{d}-L_{d} G$ are within a unit disc to remain stable. A simple rule is to choose the desired eigenvalues within the unit disc but very close to those of $S_{d}$, which are all on the unit disc. Let the eigenvalues of $S_{d}$ be $\lambda_{i}, \mathrm{i}=1,2, . ., 7$, the eigenvalues of $S_{d}-L_{d} G$ at $\rho^{*} \lambda_{I}, i=1,2, . ., 7$ with $0<p<1$. If the sampling time is very small, then $\rho$ should be very close to 1 , for example, $>0.99$.

Notice that $S_{d}$ is a seven by seven matrix. This may slow down the computation in a digital signal process. To reduce computation time, the system is decomposed into one first-order system and three second-order systems.

\subsection{System simulation and key performance evaluation}

In the block diagram shown of proposed system as in Figure 4, the nominal operating condition was chosen at $v_{s}=12 \mathrm{~V}$ and $v_{d c}=24 \mathrm{~V}$. The booster's inductance $L_{d c}=0.00033 \mathrm{H}$ and the DC-link capacitor $C_{d c}=0.00047 \mathrm{~F}$. This requires the duty cycle for the DC-DC boost converter to be $D_{0}=0.42$ and the current for the inductor $L_{d c}$ in Figure 5 to $b e \mathrm{i}_{\mathrm{L} 0}=0.9 \mathrm{~A}$.

The feedback control was found to be

$$
D=D_{0}-0.08\left(i_{L}-i_{L 0}\right)-0.06\left(v_{d c}-v_{r e f}\right)+\int\left(V_{d c}-V_{r e f}\right) d t
$$

where $v_{r e f}$ is the reference value for the DC-link voltage $v_{d c}$. The coefficients were carefully designed on the basis of good transient performance and reasonable steady state behaviour. For example, if the coefficient for $i_{L}-i_{L 0}$ is large, the duty cycle will be noisy, since the inductor current has substantial high-frequency switching ripple. If this coefficient is reduced, there will be larger overshoots in inductor current and vDC. The coefficient for $v_{d c}-v_{r e f}$ should be kept small because of the constraint on the duty cycle and the noises. Increasing the gain for the integrator may increase the overshoots and the ripple size, but the duty cycle $D$ is constrained within $[0,0.85]$ via a saturation function, as $D$ must be $<1$.

For digital implementation, this study first constructed a discretised observer to extract the first-order, secondorder harmonics and the third-order as well as their derivatives, from the state of a seventh-order LTI system. 


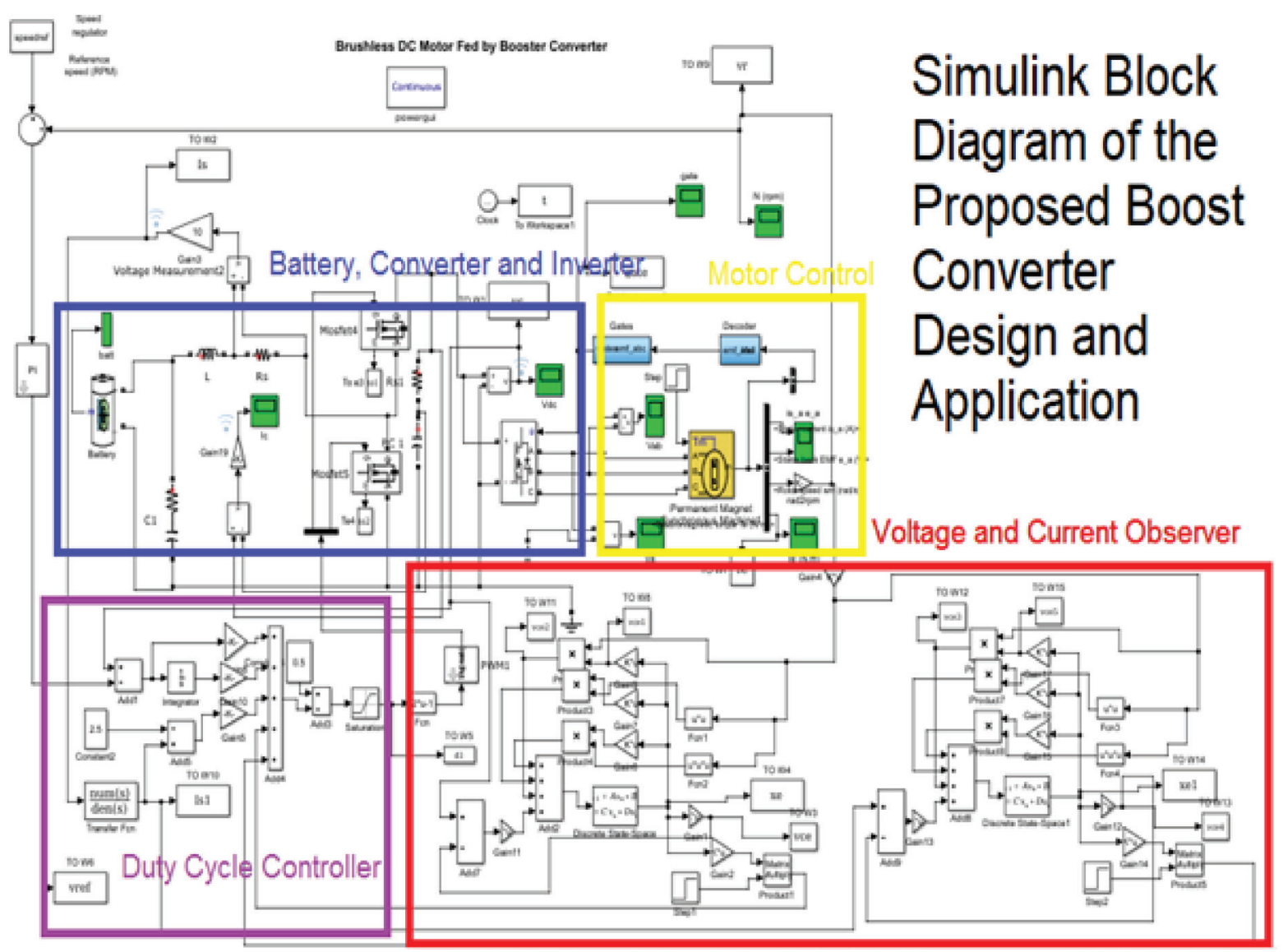

Fig. 4. Detailed harmonics observer and converter controller simulation model.

Because the real ripple frequency is $400 \mathrm{~Hz}, \beta=2 \pi \times 400=2512 \mathrm{rad} / \mathrm{s}$. With sampling frequency of $18 \mathrm{kHz}$, the sampling period is $T=5.56 \times 10^{-5} \mathrm{~s}$. The $S_{d}$ is expressed as follows:

$$
S_{d}=\left[\begin{array}{ccccccc}
1 & 0 & 0 & 0 & 0 & 0 & 0 \\
0 & 0.9903 & -0.1392 & 0 & 0 & 0 & 0 \\
0 & 0.1392 & 0.9903 & 0 & 0 & 0 & 0 \\
0 & 0 & 0 & 0.9610 & -0.2756 & 0 & 0 \\
0 & 0 & 0 & 0.2756 & 0.9610 & 0 & 0 \\
0 & 0 & 0 & 0 & 0 & 0.9123 & -0.4066 \\
0 & 0 & 0 & 0 & 0 & 0.4066 & 0.9123
\end{array}\right]
$$

The desired eigenvalues for $S_{d}-L_{d} G$ are obtained by scaling the eigenvalues of $S_{d}$ with 0.99 . Using pole placement algorithm, $L_{d}$ is computed as

$$
L_{d}=\left[\begin{array}{lllllll}
0.0098 & 0.0195 & 0.0019 & 0.0192 & 0.0037 & 0.0189 & 0.0047
\end{array}\right]^{T}
$$

As Figure 5 shows, the DC-link voltage is decomposed into a DC component and harmonics by the built observer. The first-order and second-order harmonics correspond to $z_{2}, z_{4}$ and $z_{6}$ of the observer. The $z_{3}, z_{5}$ and $z_{7}$ are similar to $z_{2}, z_{4}$ and $z_{6}$ but with phase shift.

Let's compare the original $\mathrm{v}_{\mathrm{DC}}$ signal with the reconstructed signals from the observer states. Figure 6 shows the original $\mathrm{v}_{\mathrm{DC}}$ and the reconstructed $\mathrm{v}_{\mathrm{DC}}$ signals. The estimation error is also plotted at the bottom of the figure. 
DC-Link voltage and its components

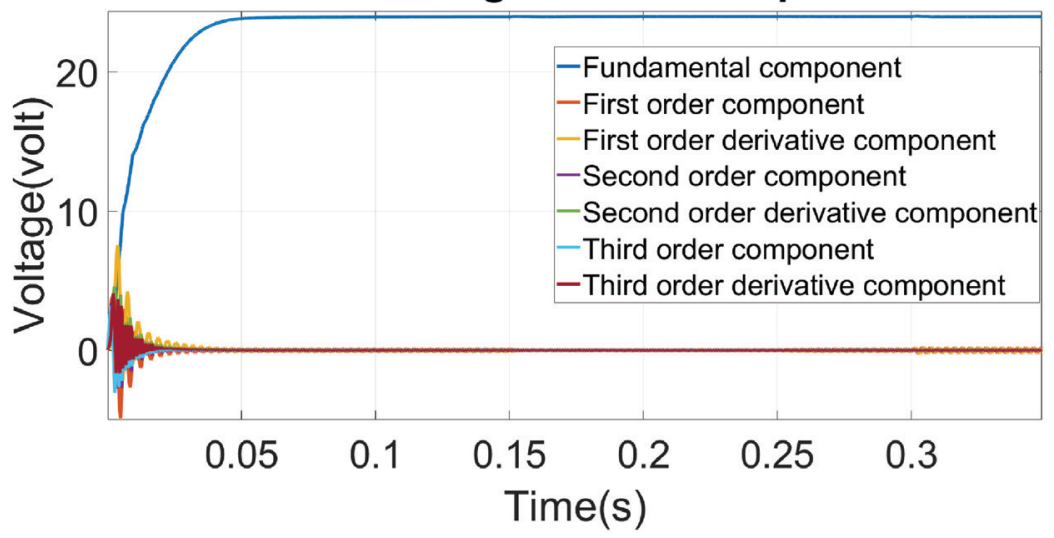

Fig. 5. Estimated DC-link voltage and its harmonics.

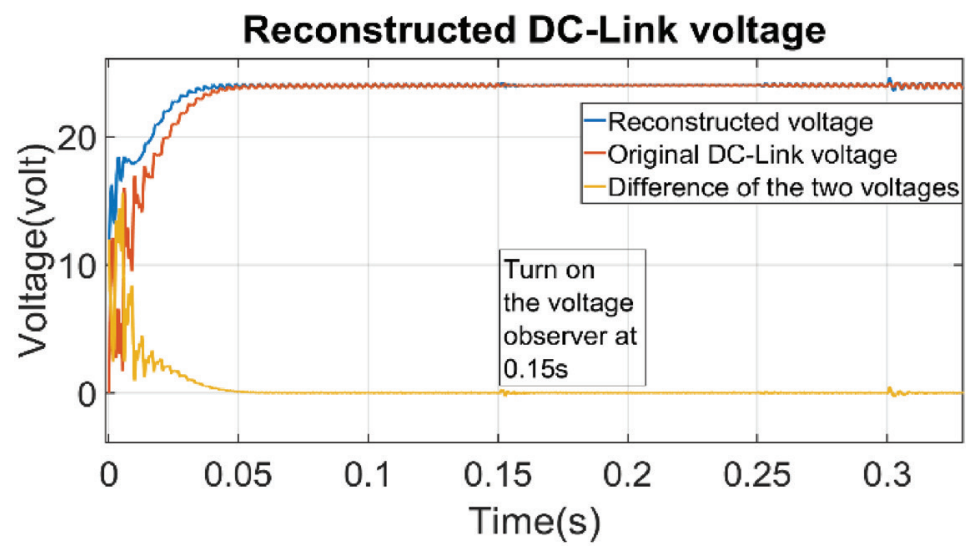

Fig. 6. Reconstructed DC-link voltage, the original voltage and the estimation error.

The comparison shows the effectiveness of the observer and shows that the seventh-order model is sufficient to estimate the DC-link signals.

It is obvious that the curve for the original VDC is fuzzy and thick, caused by the high frequency switching ripples. In contrast, the reconstructed VDC is clean and ripple free, indicating that the high frequency switching ripple has been filtered out by the observer. Since the fourth-order harmonic is negligible at steady state, the system only needs to feedback the state $z_{2}, z_{3}, z_{4}, z_{5}, z_{6}$ and $z_{7}$ to calculate the duty cycle. A state feedback is obtained through addition of two more terms, as:

$$
D=D_{0}-0.08\left(i_{L}-i_{L 0}\right)-0.06\left(v_{d c}-v_{r e f}\right)+\int\left(v_{d c}-v_{r e f}\right) d t-0.3 z_{2}+0.2 z_{3}-0.1 z_{4}+0.2 z_{5}-0.03 z_{6}+0.14 z_{7}
$$

First, the term for $z_{3}$ is set at 0 . By using a one-dimensional search and simulation, it is found that the ripple is minimum when the coefficient of $z_{2}$ is -0.3 . Another one-dimensional search, with the coefficient of $z_{2}$ fixed at -0.3 , produced a value of 0.2 for $z_{3}$. These two coefficients are obtained through trial and error. Other coefficients are then determined in the same way.

It should be noted that both terms for $z_{2}$ and $z_{3}$ are needed to minimise ripple size. If the term for $z_{3}$ is discarded, the minimum ripple size increases. This means that the derivative of the firs-order harmonic helps to reduce the ripple size. The same applies to other harmonics.

In order to eliminate the output voltage overshoot and vibration caused by the observer feedback at the beginning, a delay element is added to the observer feedback loop at $0.15 \mathrm{~s}$ (Arogbonlo et al., 2019). The Figure 7 demonstrates how the observer state in Eq. (15) is fed back by a multiplied feedback gain K in Eqs (12) and (19) 


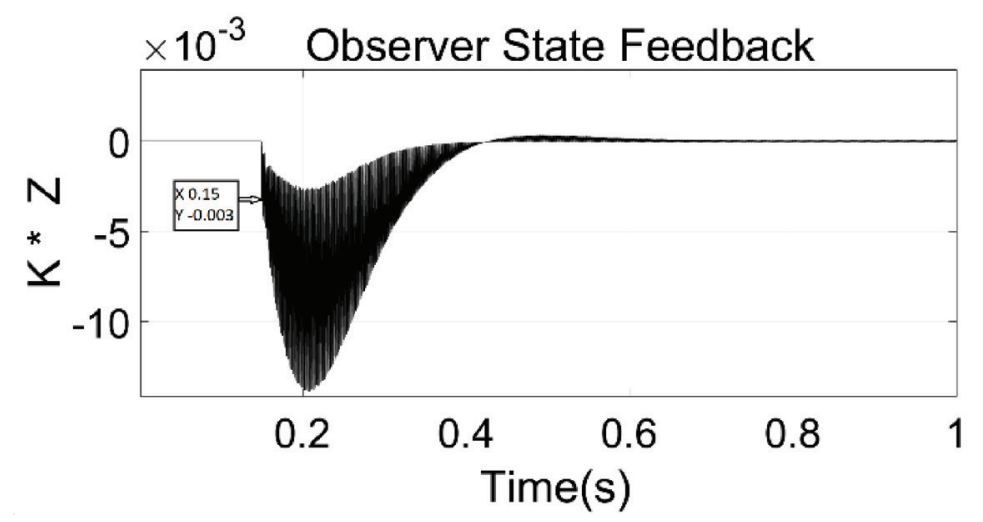

Fig. 7. The feedback signal starts at $0.15 \mathrm{~s}$ and it equals to the observer state $\mathrm{Z}$ multiplied by a proper gain $\mathrm{K}$.

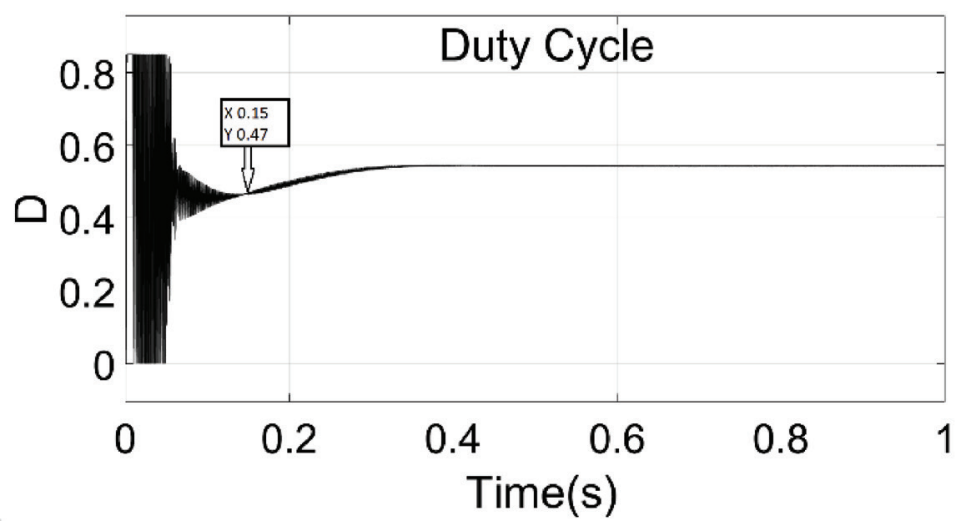

Fig. 8. The simulation waveform of the duty cycle constrained within $[0,0.85]$.

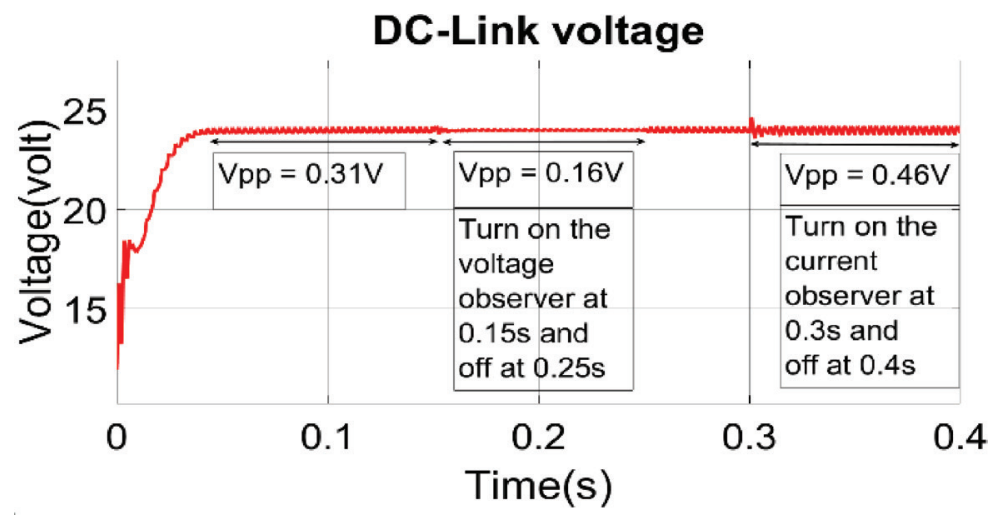

Fig. 9. DC-link voltage ripple reduced by $48 \%$ from $0.15 \mathrm{~s}$ to $0.25 \mathrm{~s}$.

to implement ripple cancellation. The observer state feedback starts from $0.15 \mathrm{~s}$. Figure 8 shows the waveform for the duty cycle $D$ in Eq. (19) and $D$ lies in the range $0-0.85$ via a saturation function. The MOSFET switch gate drive signal for the boost converter is modulated by the duty ratio $D$.

To observe the effect more accurately, more load is connected to the motor. This load torque change increases the DC-link voltage and the voltage ripples. Simulink is used to conduct the simulation of the proposed control system. The sampling rate can be chosen as $18 \mathrm{kHz}$. The motor model runs at $800 \mathrm{rpm}$ and speed controller requires $24 \mathrm{~V} \mathrm{DC}$ that is the reference output voltage of the boost converter. The DC-link voltage and inductor current generated by the boost converter are controlled by the proposed controller and the voltage and current 
Inductor current

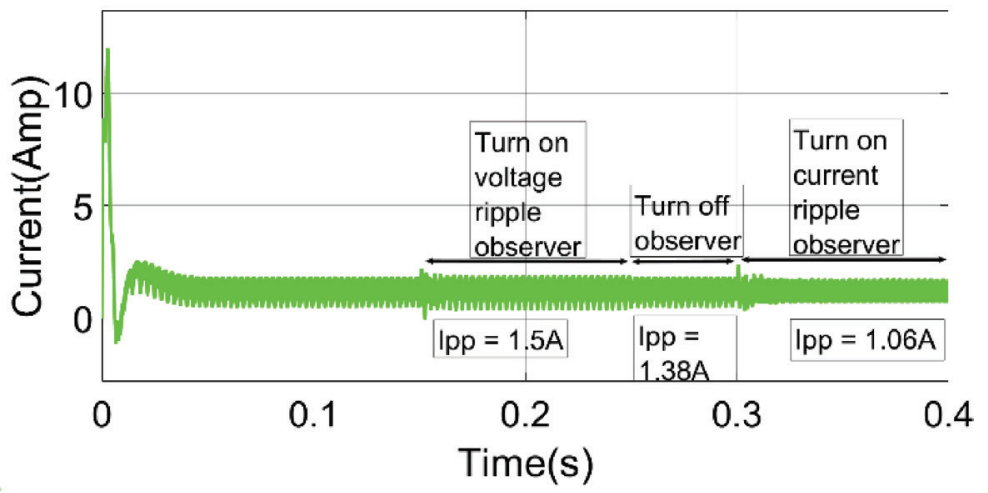

Fig. 10. The proposed controller can also reduce the magnitude of current ripples by about $23 \%$ after $0.3 \mathrm{~s}$.

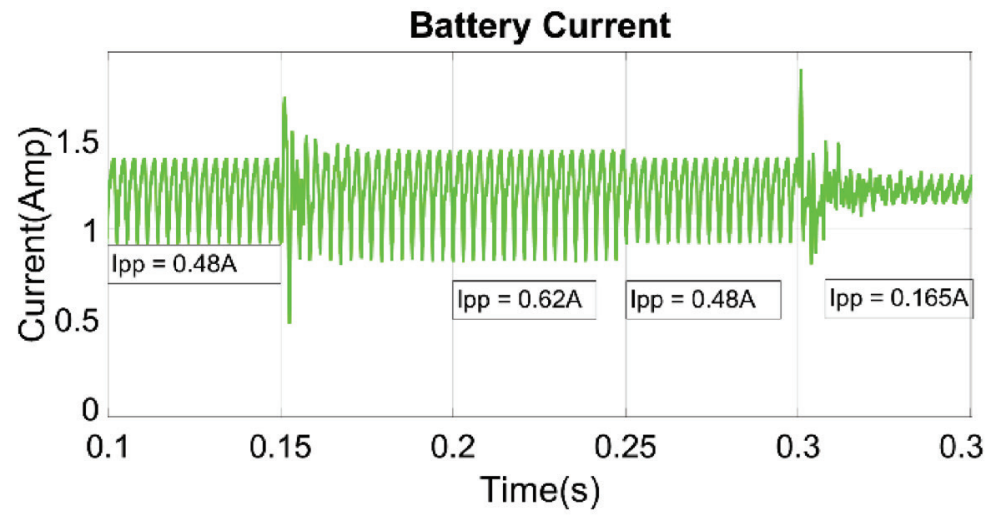

Fig. 11. The battery ripple current can also be reduced by about $66 \%$ after $0.3 \mathrm{~s}$.

waveforms are plotted in Figures 9-11. Figure 8 shows that the peak-to-peak voltage ripple amplitude is quickly reduced by $48 \%$ from $0.31 \mathrm{~V}$ to $0.16 \mathrm{~V}$ by turning on the voltage harmonics states feedback at $0.15 \mathrm{~s}$.

In similarity to the voltage ripple reduction principle, current ripple observers can also be built in current states feedback control with proper gains to reduce both the battery ripple current and inductor current ripple. The redesigned observer feedback gain was also gained by a one-dimensional search and simulation. The peak to peak inductor current ripple amplitude is reduced by about $23 \%$ from $1.38 \mathrm{~A}$ to $1.06 \mathrm{~A}$ in Simulink simulation after $0.3 \mathrm{~s}$ as shown in Figure 10.

The simulation model uses a Lead-acid battery as DC power source that is modelled in a first-order R-C model by MATLAB/Simulink. The battery parameters such as voltage, current and capacity are also measured by the battery model (Lee et al., 2011). As we know, the ripple current has negative impact on battery capacity and impedance if the high frequency ripple is not properly reduced. Furthermore, the high frequency ripple current will reduce battery life and degrade the operation of motor drive system. Using the proposed method, the battery ripple current magnitude can be reduced from $0.48 \mathrm{~A}$ to $0.16 \mathrm{~A}$ after the current harmonics' states are used in the proposed feedback control, as shown in Figure 11.

But the voltage ripple and the current ripple cannot be reduced at the same time by the proposed harmonic feedback control. It is shown in the Figures 9-11 that when the voltage ripple is reduced, the current ripple becomes greater and vice versa.

\subsection{Tune the gain of cascade control loop}

The BLDC motor is controlled by a PI-based cascade controller including an outer speed control and an inner converter control loop. The boost converter voltage is regulated through the observer-based converter controller. The BLDC motor with a trapezoidal back-EMF is driven by a controlled three-phase inverter. 
To turn the cascade control loops, we first tuned the inner converter voltage loop when the outer speed loop is left open. Then we calculated the outer speed PI controller when the inner loop is closed. To achieve a good balance between performance and robustness, both inner and outer controllers should have a phase margin of $60^{\circ}$. To ensure that the inner converter voltage controller has a faster response than the outer speed controller, the outer speed control will have a target bandwidth of $100 \mathrm{rad} / \mathrm{s}$ and the inner voltage loop will have an estimated target bandwidth of $400 \mathrm{rad} / \mathrm{s}$.

In simulation, some predefined speed steps are used as reference speed input to test PI speed controller performance. The reference speed for testing speed tracking performance is a series of speed ramps from $2,000 \mathrm{rpm}$ to $2,500 \mathrm{rpm}$ and $2,500 \mathrm{rpm}$ to $2,000 \mathrm{rpm}$. Simulating the model with tuned controller gains shows good tracking performance of the speed controller. Figure 12 indicates that the outer PI controller provides a quick and accurate tracking of the reference rotor speed. The Figure 13 shows the inner voltage controller tracking the DC-link reference voltage with fast response and minor overshoot. When rotor speed keeps constant at 2,000 rpm, the proposed harmonics feedback controller is able to reduce the speed ripple as shown in Figure 14 due to the positive linear relationship between the motor speed and its DC supply voltage.

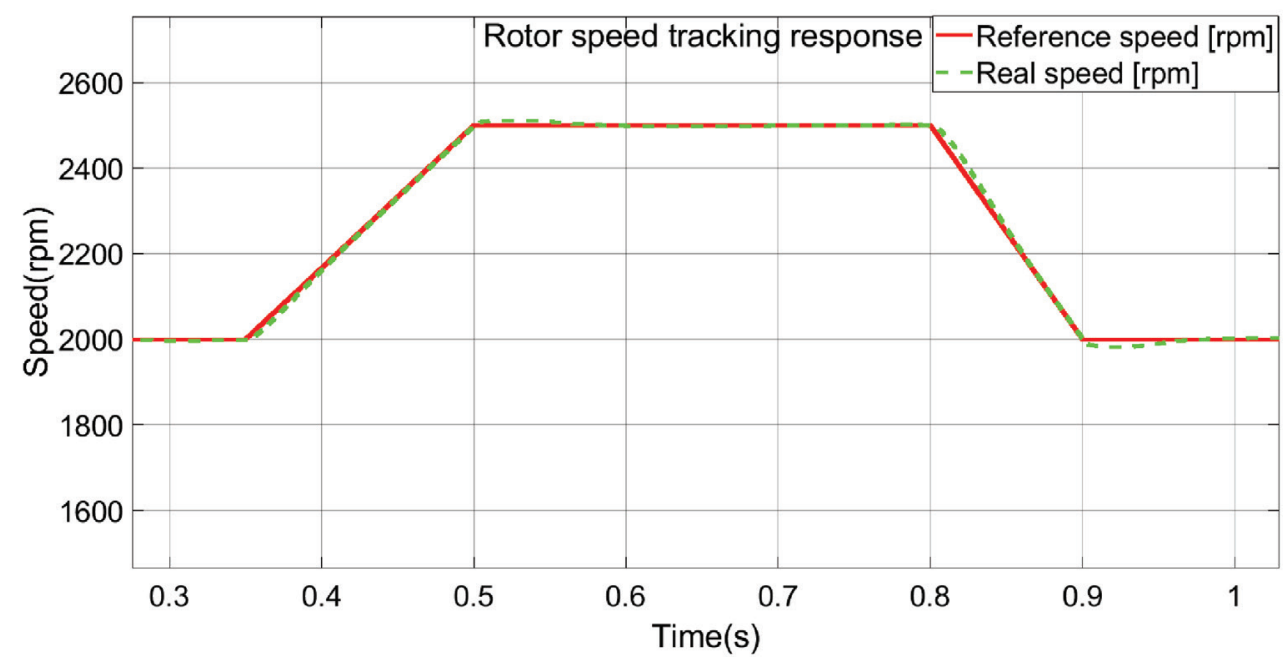

Fig. 12. Speed control response curves.

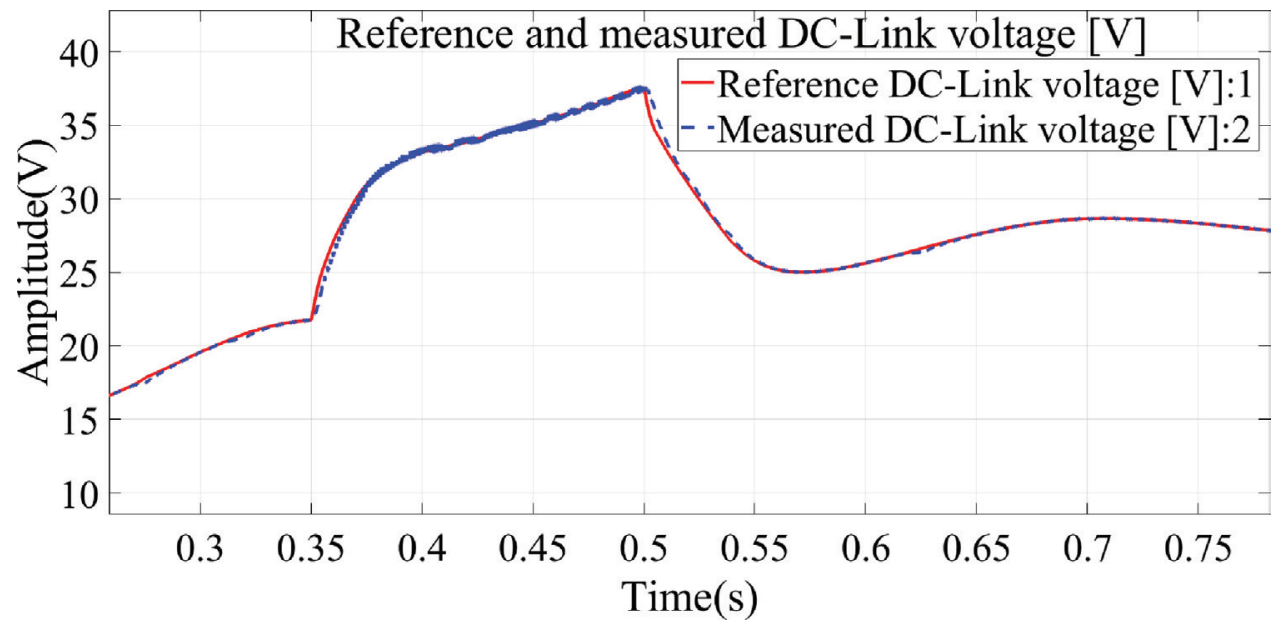

Fig. 13. Booster output voltage tracks voltage reference values. 


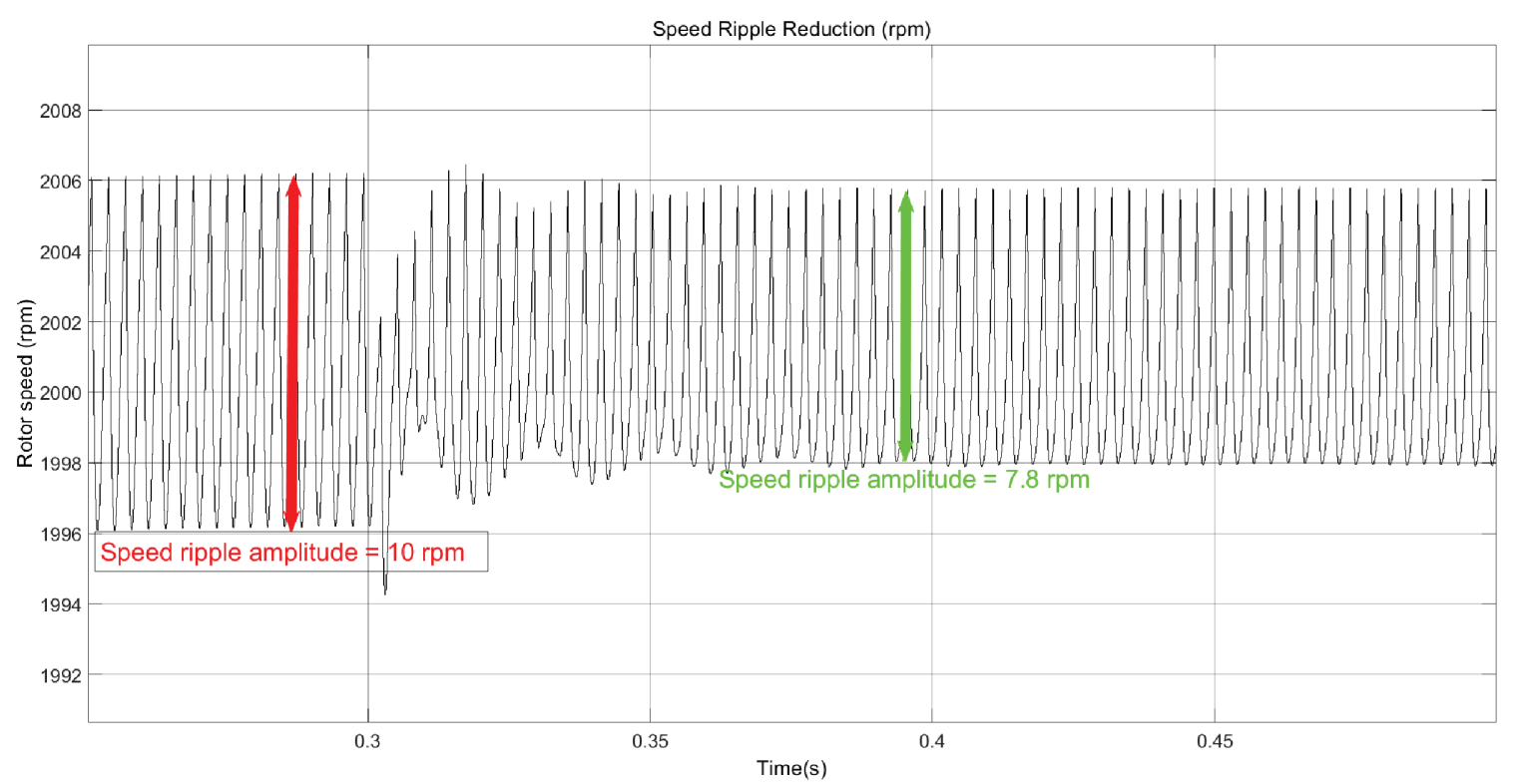

Fig. 14. Rotor speed ripple can be reduced due to DC-link voltage ripple reduction.

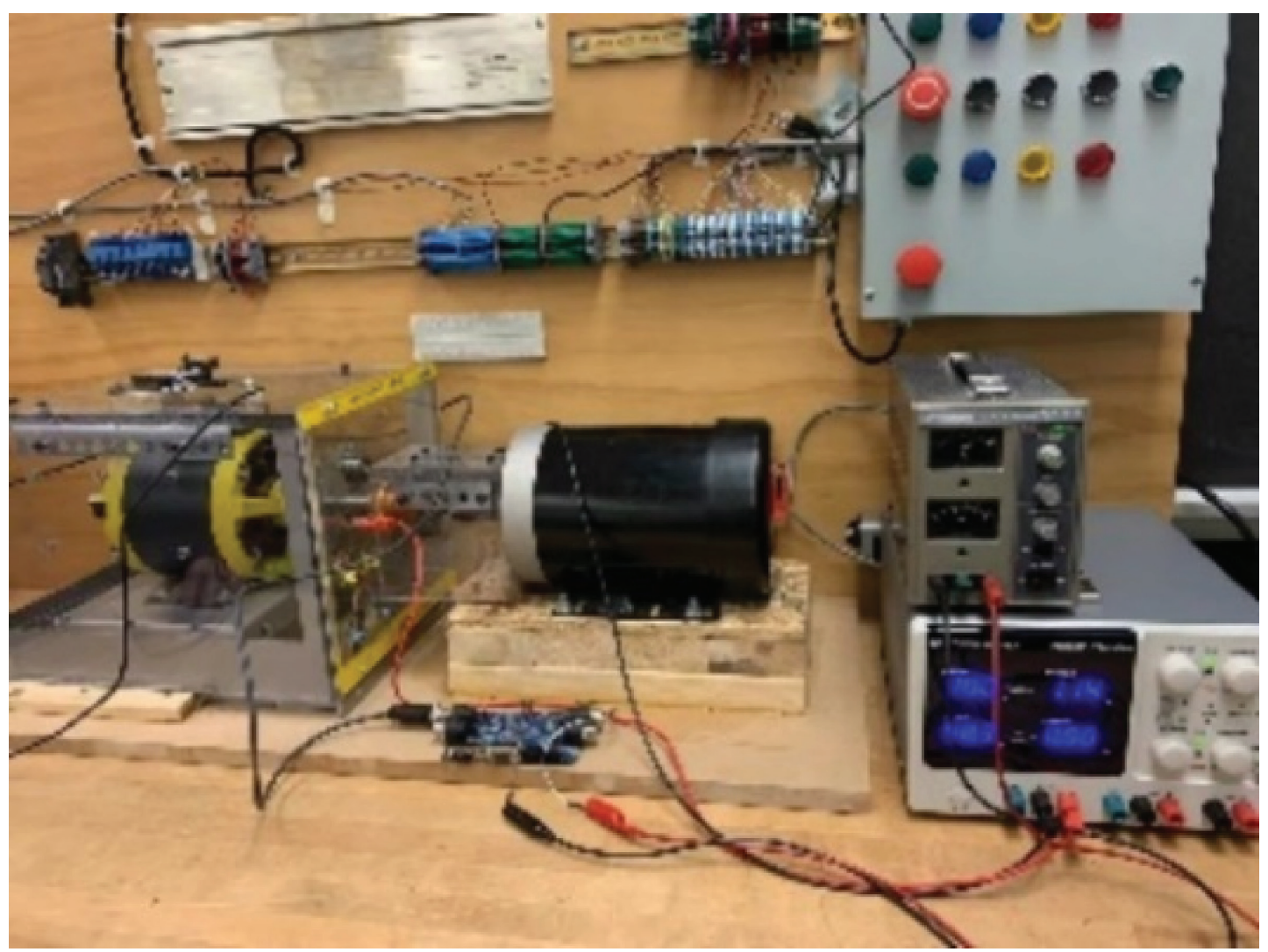

Fig. 15. Experiment platform includes a BLDC drive motor, a load motor, and a microcontroller board and a drive board. BLDC, brushless DC

\section{Experimental Results}

In the experimental test shown in Figure 15, we designed a boost converter that output $24.4 \mathrm{~V}$ to power an inverter and drive a BLDC motor. The $24.4 \mathrm{~V}$ BLDC supply voltage is pre-scaled in relation to the rated voltage for BLDC 
Table 2. BLDC motor parameters

\begin{tabular}{ll}
\hline Symbols & Meanings \\
\hline \hline Number of phases & 3 \\
Back EMF waveform & Trapezoidal \\
Stator phase resistance $(\mathrm{ohm})$ & 0.41 \\
Stator phase inductance $(\mathrm{H})$ & 0.0007 \\
Torque constant $(\mathrm{N} / \mathrm{M} / \mathrm{A}$-peak) & 1.4 \\
Back EMF flat area (degrees) & 120 \\
Inertia $\left(\mathrm{J}\left(\mathrm{kg} / \mathrm{m}^{2}\right)\right)$ & $9.6 \mathrm{e}-5$ \\
Pole pairs & 4 \\
\hline
\end{tabular}

BLDC, brushless DC.

Table 3. Battery parameters

\begin{tabular}{ll}
\hline Symbols & Meanings \\
\hline \hline Electrical characteristics at 25 C & $12 \mathrm{~V} 7 \mathrm{~s}$ \\
Nominal voltage & $13.2 \mathrm{~V}$ \\
Nominal capacity & $5 \mathrm{Ah}$ \\
Maximum charge voltage & $16 \mathrm{~V}$ \\
Recommended float voltage & $13.6-14.4 \mathrm{~V}$ \\
Under-voltage limit (min) & $8 \mathrm{~V}$ \\
Constant power discharge end voltage & $10 \mathrm{~V}$ \\
\hline
\end{tabular}

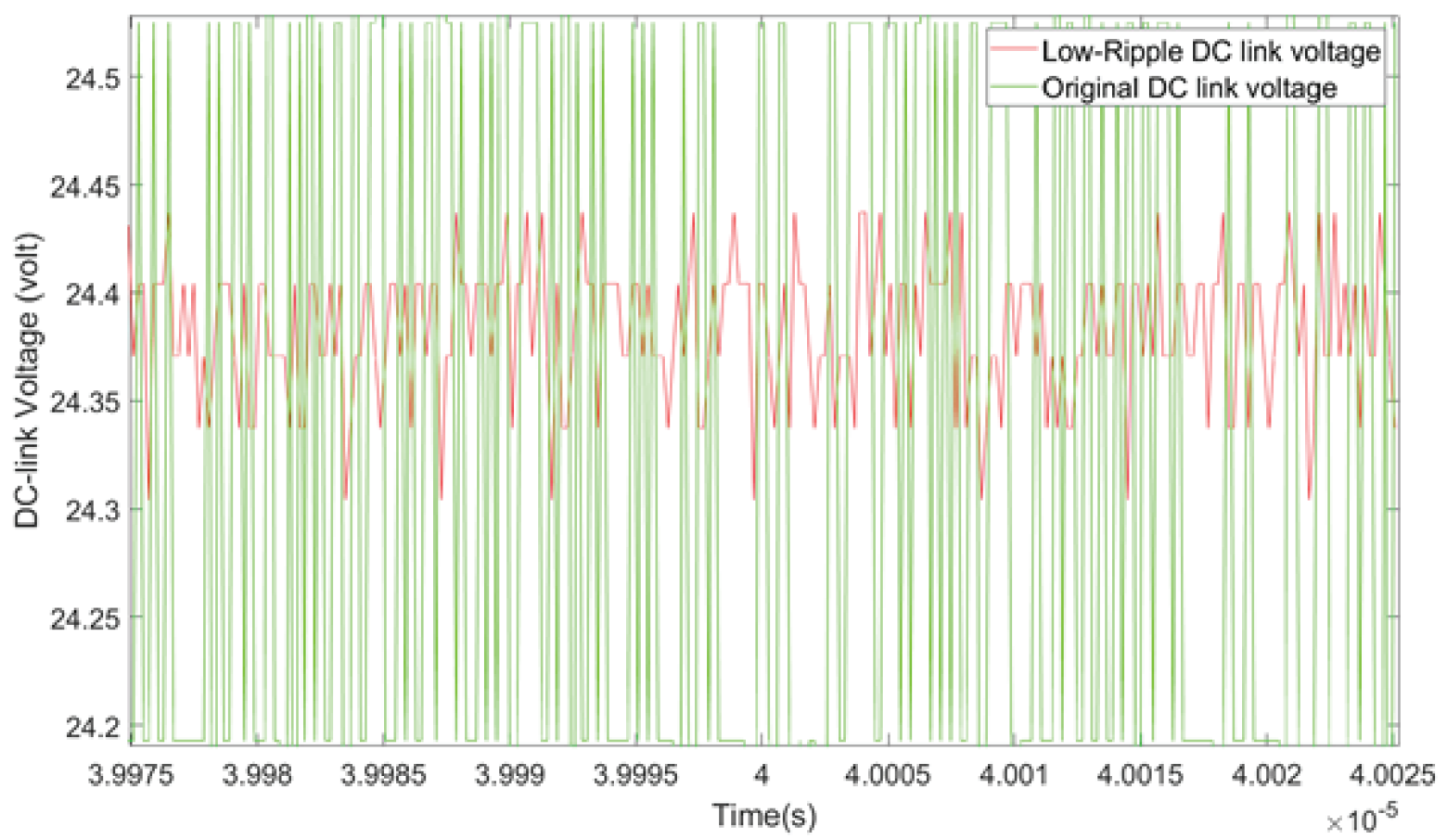

Fig. 16. Original DC-link voltage ripple compared with reduced voltage ripple under the proposed control.

motors used in prospective full-scale EVs in which rated voltage is from $36 \mathrm{~V}$ to $95 \mathrm{~V}$ (Racewicz et al., 2018). The DC-link voltage was measured by an oscilloscope and saved in binary files before and after the proposed harmonics feedback control was used to control the boost converter. The TMS320F28335 digital signal controller (DSC) developed and ran C code for the proposed embedded control system. The main code flow chart diagram is shown in addendum. 


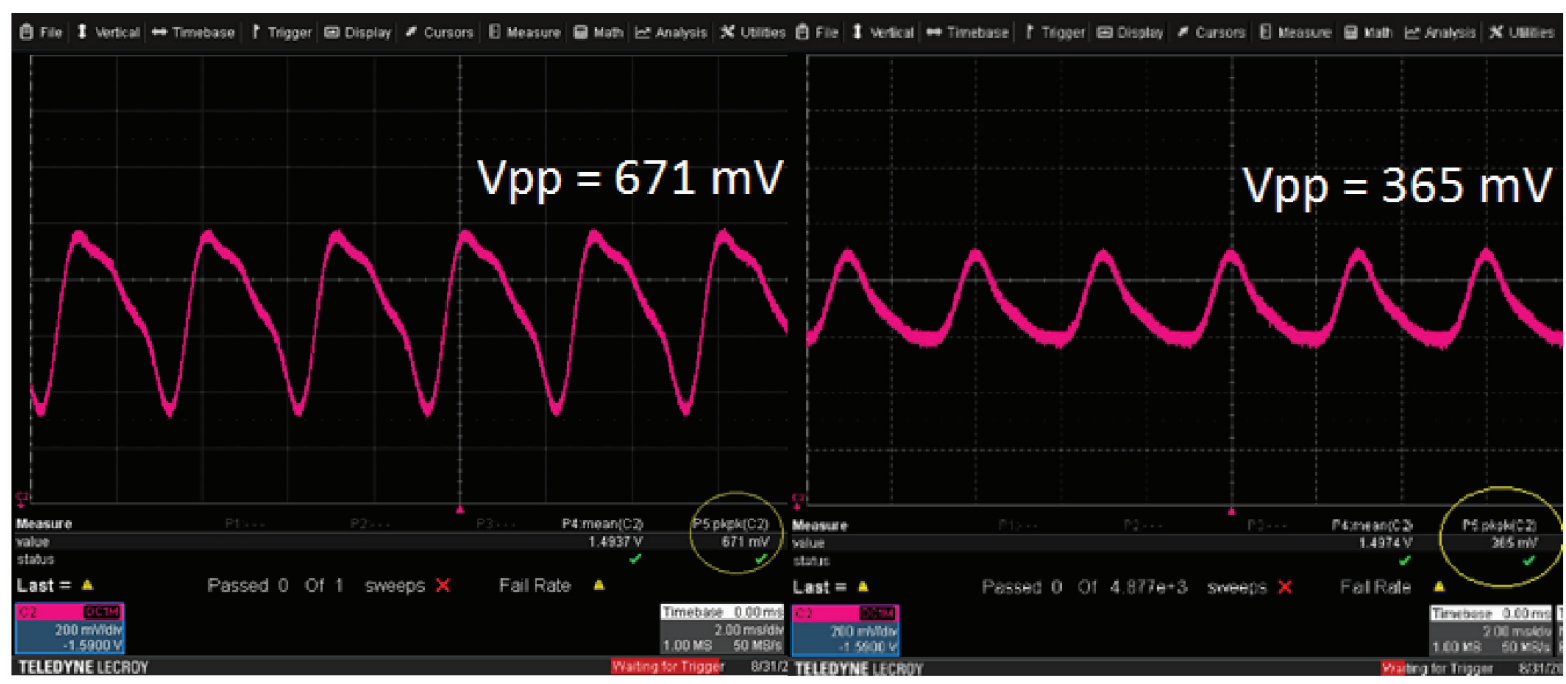

(a)

(b)

Fig. 17. (a) Original DC-link voltage ripple, (b) Reduced voltage ripple under the proposed control.

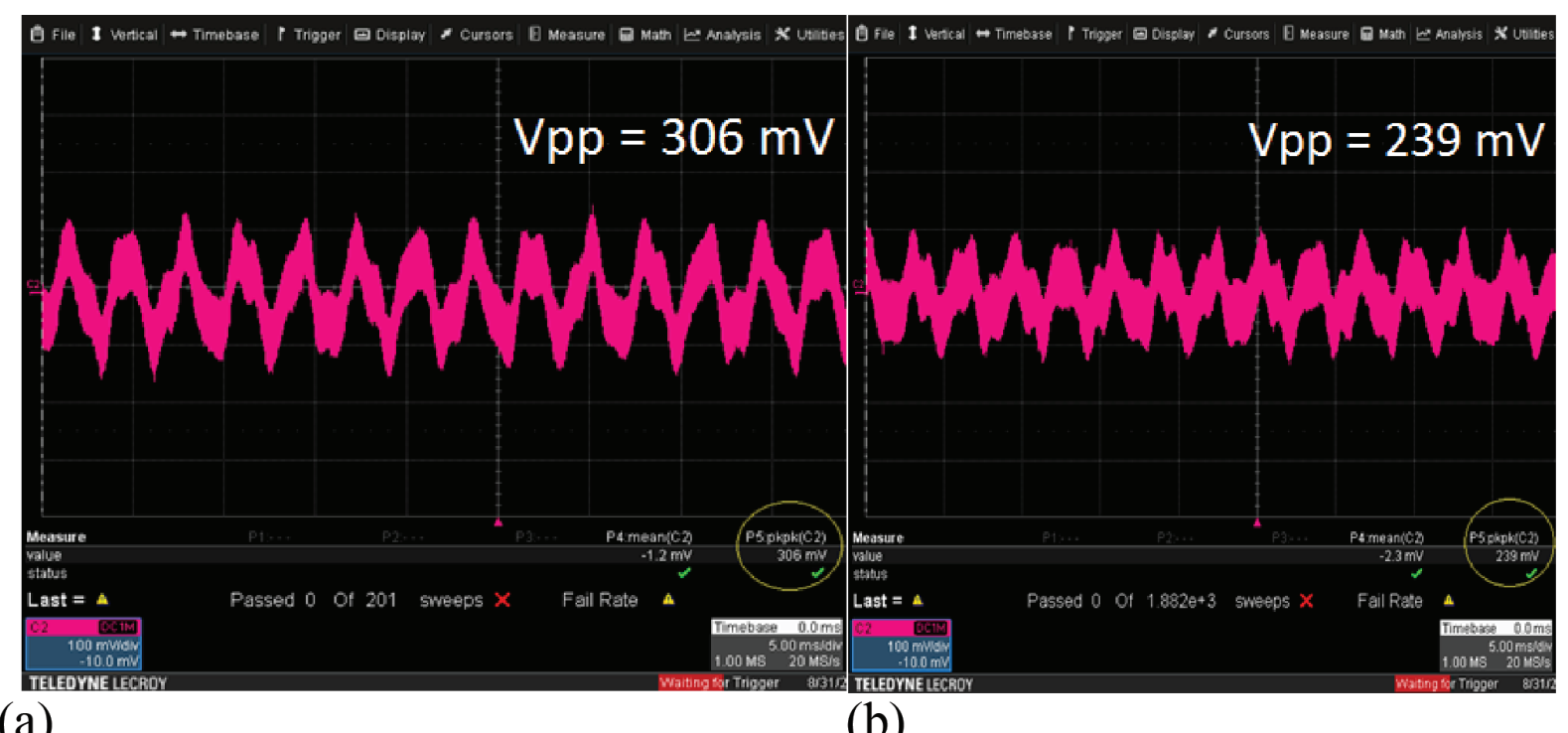

(a)

(b)

Fig. 18. (a) Original voltage ripple represents the inductor original current ripple, (b) Reduced voltage ripple shows the reduction of the current ripple.

The detailed experiment parameters are shown in Tables 2 and 3 (Wang, 2019).

The switching frequency for both the boost converter and the inverter was $18 \mathrm{kHz}$. The sampling frequency for the microcontroller was also $18 \mathrm{kHz}$. The DC-link voltage ripple of the boost converter was sampled and the raw data were imported into MATLAB and plotted in Figure 16 for observation and comparison. The figure shows that the DC-link voltage ripple can be reduced significantly by the proposed controller. In order to observe the specific harmonics reduction, DC components and unrelated noise were removed from signals in the oscilloscope. Figure 10 shows that DC-link voltage ripple peak to peak value is reduced by $46 \%$, from $671 \mathrm{mV}$, as shown in Figure 17(a), to $365 \mathrm{mV}$, as shown in Figure 17(b). This reduction ratio is approximately equal to that in the simulation test shown in Figure 9.

The boost converter circuit used a $0.1 \mathrm{ohm}$ resistor connected in series with an inductor to measure the current flowing through the inductor $L_{d c}$. Figure 18 shows the current ripple represented by the voltage across the $0.1 \mathrm{ohm}$ resistor. The resistor's peak-to-peak voltage is reduced by $22 \%$, from $306 \mathrm{mV}$, in Figure $18(\mathrm{a})$, to $239 \mathrm{mV}$, in 
Figure 18(b). This ratio of ripple reduction is also close to the ratio in the simulation shown in Figure 10. The experiments proved the proposed method can effectively reduce voltage or current ripple when using the harmonics estimation states in the feedback control to calculate the duty cycle and control the boost converter.

\section{Conclusion}

This research addressed boost converter ripple reduction problems associated with an inverter and a BLDC drive circuit and a control strategy for the DC-link ripple reduction is proposed for a two-stage booster inverter circuit. The main idea is to use observers to extract the harmonics of the DC-link voltage and current, and then use the harmonics states in feedback control for the boost converter. The measured motor speed can also be used to adaptively adjust the frequency of the harmonics estimated by the observers.

\section{References}

Aljarajreh, H., Lu, D. D. and Tse, C. K. (2019). Synthesis of Dual-Input Single-Output DC/DC Converters. 2019 IEEE International Symposium on Circuits and Systems (ISCAS), pp. 1-5.

Amamra, S. A., Tripathy, Y., Barai, A., Moore, A. D. and Marco, J. (2020). Electric Vehicle Battery Performance Investigation Based on Real World Current Harmonics. Energies, 13(2), pp. 489.

Arogbonlo, A., Trinh, H. and Oo, A. M. T. (2019). Design of Observers for Positive Systems with Delayed Input and Output Information. IEEE Transactions on Circuits and Systems II: Express Briefs, 67(1), pp. 107-111.

Axelrod, B., Berkovich, Y., Tapuchi, S. and Ioinovici, A. (2009). Single-Stage Single-Switch SwitchedCapacitor Buck/Buck-Boost-Type Converter. IEEE Transactions on Aerospace and Electronic Systems, 45(2), pp. 419-430.

Bamgboje, D. O., Harmon, W., Tahan, M. and Hu, T. (2019). Low Cost High Performance Led Driver Based on a Self-Oscillating Boost Converter. IEEE Transactions on Power Electronics, 34(10), pp. 10021-10034.

Chen, T.-C., Shieh, S. H. and Ren, T.-J. (2017). Torque Ripple Reduction of Brushless DC Motor Using Genetic Algorithm. Proceedings of the 4th
Although using harmonics as feedback could make the controller more complex, the PI coefficients of the cascade controller can be fine-tuned by simple frequency response techniques. The simulation results showed that PI controller has a good performance in the speed control and fast-tracking response to DC voltage regulation. Moreover, the boost converter can reduce the DC-link voltage ripple, inductor current ripple, the battery ripple current as well as rotor speed ripple significantly. The experimental results were used to prove that the reduction of both $\mathrm{DC}$-link voltage ripple and current ripple can be achieved in both simulation and the real circuit. Since the ripple reduction is achieved by the feedback control of harmonics observer states, the proposed method can also be used to reduce other similar fixed frequency ripples in other applications.

\section{Acknowledgments}

This work was supported by Penn State University Research and Development Grant.

international conference on control, dynamic systems, and robotics, Toronto, ON, Canada, pp. 21-23.

Darba, A., De Belie, F. and Melkebeek, J. A. (2015). A Back-Emf Threshold Self-Sensing Method to Detect the Commutation Instants in BLDC Drives. IEEE Transactions on Industrial Electronics, 62(10), pp. 6064-6075.

Deng, X., Mecrow, B., Wu, H. and Martin, R. (2017). Design and Development of Low Torque Ripple Variable-Speed Drive System with Six-Phase Switched Reluctance Motors. IEEE Transactions on Energy Conversion, 33(1), pp. 420-429.

Devarakonda, L., Wang, H. and Hu, T. (2014). Parameter Identification of Circuit Models for Lead-Acid Batteries under Non-Zero Initial Conditions. 2014 American Control Conference, pp. 4360-4365.

Doss, M., Dash, S., Mahesh, D. and Marthandan, V. (2013). A Model Predictive Control to Reduce Torque Ripple for Brushless DC Motor with Inbuilt Stator Current Control. Universal Journal of Electrical and Electronic Engineering, 1(3), pp. 59-67.

Fassinou, F., Wang, H., Devarakonda, L. and Hu, T. (2014). Observer-Based Method for Reduction of DC-Link Voltage Ripple in Two-Stage Boost 
Inverters. 2014 American Control Conference, pp. 4348-4353.

Forouzesh, M., Siwakoti, Y. P., Gorji, S. A., Blaabjerg, F. and Lehman, B. (2017). Step-up DC-DC Converters: A Comprehensive Review of VoltageBoosting Techniques, Topologies, and Applications. IEEE Transactions on Power Electronics, 32(12), pp. 9143-9178.

Gu, Y. and Zhang, D. (2012). Interleaved Boost Converter with Ripple Cancellation Network. IEEE Transactions on Power Electronics, 28(8), pp. 3860-3869.

Hu, T., Teel, A. R. and Lin, Z. (2005). Lyapunov Characterization of Forced Oscillations. Automatica, 41(10), pp. 1723-1735.

Jung, H., Wang, H. and Hu, T. (2014). Control Design for Robust Tracking and Smooth Transition in Power Systems with Battery/Supercapacitor Hybrid Energy Storage Devices. Journal of Power Sources, 267, pp. 566-575.

Lee, W., Han, B.-M. and Cha, H. (2011). Battery Ripple Current Reduction in a Three-Phase Interleaved DC-DC Converter for 5kw Battery Charger. 2011 IEEE Energy Conversion Congress and Exposition, pp. 3535-3540.

Liu, W., Wang, Z., Wang, G., Zeng, Q., He, W., Liu, L., Wang, X., Xi, Y., Guo, H., Hu, C. and Wang, Z. L. (2020). Switched-Capacitor-Convertors Based on Fractal Design for Output Power Management of Triboelectric Nanogenerator. Nature Communications, 11(1), pp. 1883.

Nahavandi, A., Hagh, M. T., Sharifian, M. B. B. and Danyali, S. (2015). A Nonisolated Multiinput Multioutput DC-DC Boost Converter for Electric Vehicle Applications. IEEE Transactions on Power Electronics, 30(4), pp. 1818-1835.

Nguyen, B. L. H., Cha, H., Nguyen, T. T. and Kim, H. G. (2018). Family of Integrated Multi-Input Multi-Output DC-DC Power Converters. 2018 International Power Electronics Conference (IPECNiigata 2018 -ECCE Asia), pp. 3134-3139.

Prathibanandhi, K. and Ramesh, R. (2018). Hybrid Control Technique for Minimizing the Torque Ripple of Brushless Direct Current Motor. Measurement and Control, 51(7-8), pp. 321-335.

Racewicz, S., Kazimierczuk, P., Kolator, B. and Olszewski, A. (2018). Use of 3 Kw BLDC Motor for Light Two-Wheeled Electric Vehicle Construction. IOP Conference Series: Materials Science and Engineering, 421(4), pp. 042067.

Rashed, M., Klumpner, C. and Asher, G. (2010). High Performance Multilevel Converter Topology for Interfacing Energy Storage Systems with Medium Voltage Grids. IECON 2010-36th Annual Conference on IEEE Industrial Electronics Society, pp. 1825-1831.

Shi, H., Wen, H., Hu, Y. and Jiang, L. (2018). Reactive Power Minimization in Bidirectional DC-DC Converters Using a Unified-Phasor-Based Particle Swarm Optimization. IEEE Transactions on Power Electronics, 33(12), pp. 10990-11006.

Tay, H. Q., Nam, V. T., Duc, N. H. and Chau, B. N. (2012). A Current Sensing Circuit Using Current-Voltage Conversion for Pmos-Based LDO Regulators. 2012 International Symposium on Computer Applications and Industrial Electronics (ISCAIE), pp. 1-4.

Tofoli, F. L., Pereira, D. D. C., Josias De Paula, W. and Oliveira Júnior, D. D. S. (2015). Survey on NonIsolated High-Voltage Step-up DC-DC Topologies Based on the Boost Converter. IET Power Electronics, 8(10), pp. 2044-2057.

Uddin, K., Moore, A. D., Barai, A. and Marco, J. (2016). The Effects of High Frequency Current Ripple on Electric Vehicle Battery Performance. Applied Energy, 178, pp. 142-154.

Ullah, S. (2021). Robust Back-Stepping Based Higher Order Sliding Mode Control of NonInverted Buck-Boost Converter for a Photovoltaic System. Power Electronics and Drives, 6(1), pp. 113-127.

Wang, H. (2019). A Boost Converter Design with Low Output Ripple Based on Harmonics Feedback. arXiv preprint arXiv:1901.10020.

Wang, H. and Hu, T. (2020). Multichannel Sequential Display Led Driver with Optimal Transient Performance and Efficiency Via Synchronous Integral Control. IET Power Electronics [Online], 13(15), pp. 3226-3233. Available at: https://digitallibrary.theiet.org/content/journals/10.1049/ietpel.2020.0128.

Wang, H., Tahan, M. and Hu, T. (2016). Effects of Rest Time on Equivalent Circuit Model for a LiIon Battery. 2016 American Control Conference (ACC), pp. 3101-3106.

Waradzyn, Z., Stala, R., Skała, A., Mondzik, A. and Penczek, A. (2018). A Cost-Effective Resonant Switched-Capacitor DC-DC Boost Converter Experimental Results and Feasibility Model. Power Electronics and Drives, 3(38), pp. 75-83.

Wen, H. and Su, B. (2016). Hybrid-Mode Interleaved Boost Converter Design for Fuel Cell Electric Vehicles. Energy Conversion and Management, 122, pp. 477-487. 
Wen, H., Xiao, W. and Su, B. (2014). Nonactive Power Loss Minimization in a Bidirectional Isolated DCDC Converter for Distributed Power Systems. IEEE Transactions on Industrial Electronics, 61(12), pp. 6822-6831.

Wu, C., Chen, J., Xu, C. and Liu, Z. (2016). Adaptive Control Strategy of a Fuel Cell/Battery Hybrid Power System. 2016 American Control Conference (ACC), pp. 7492-7497.

Yang, P., Chi, K. T., Xu, J. and Zhou, G. (2015). Synthesis and Analysis of Double-Input Single-Output DC/
DC Converters. IEEE Transactions on Industrial Electronics, 62(10), pp. 6284-6295.

Zhang, Z., Wei, H., Zhang, W. and Jiang, J. (2021). Ripple Attenuation for Induction Motor Finite Control Set Model Predictive Torque Control Using Novel Fuzzy Adaptive Techniques. Processes, 9(4), pp. 710.

Zhong, Q.-C. and Konstantopoulos, G. C. (2016). Nonlinear Current-Limiting Control for Grid-Tied Inverters. 2016 American Control Conference (ACC), pp. 7472-7477. 


\section{Appendix}

The flow chart of the proposed control system software implementation in DSP.

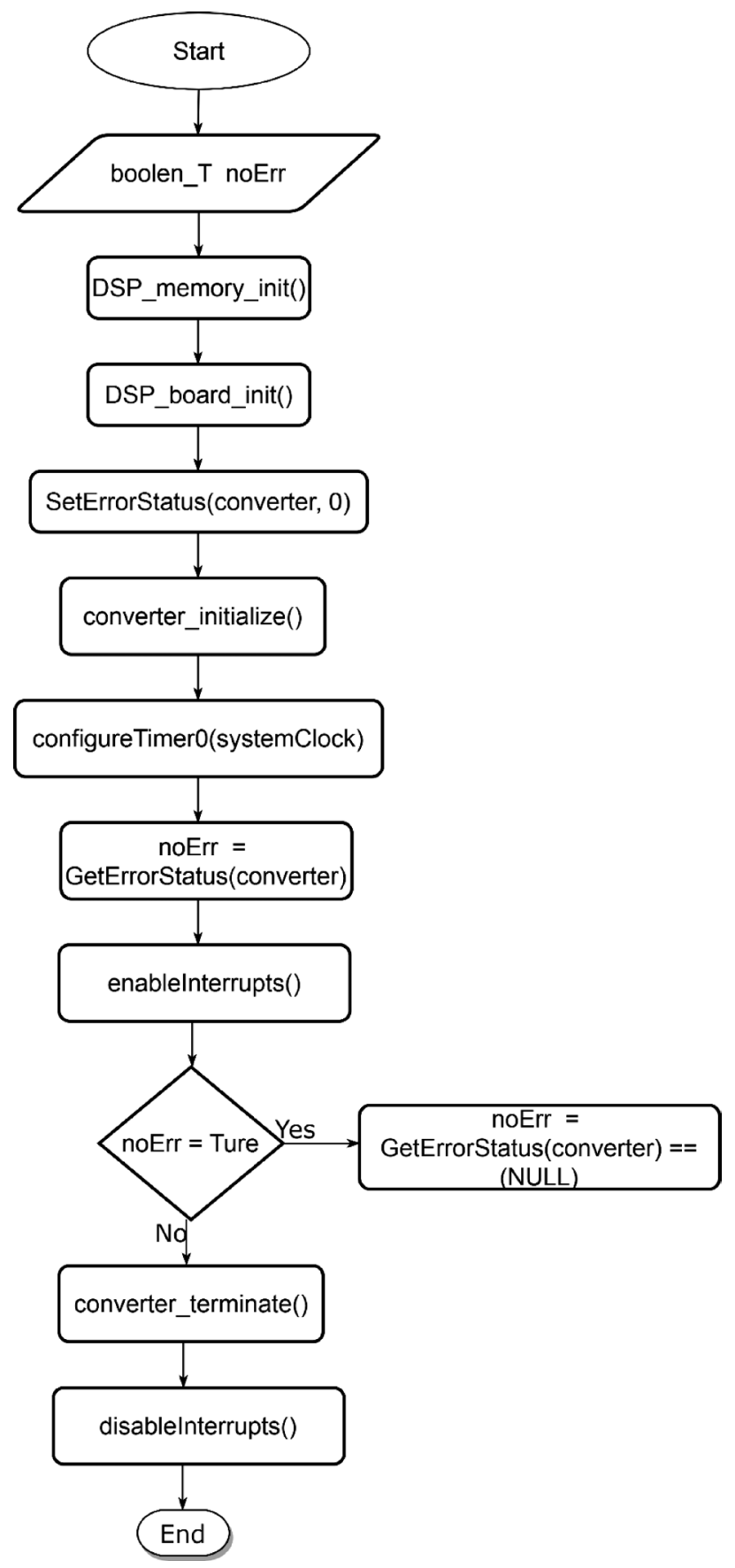

